${ }^{2}$ Department of Health and Social Security. Recommended daily amounts of food energy and nutrients for groups of people in the United Kingdom. Reports on health and social subjects. No 15. London: HMSO, 1979.

4 Shahinian AH, Reinhold JG. Application of the phenol-hypochlorite reaction to measurement of ammonia concentrations in Kjeldhal digests of serum and various tissues. Clin Chem 1971;17:1077-80.

4 Yatzidis H, Oreopoulous D, Symvoulidis A, Triantaphyllidis D, Yannitsiotis A. Une methode simple pour le dosage des sulfates dans les serum et l'urine. Revue Française d'Études Cliniques et Biologiques $1964 ; 9: 126-33$.

${ }^{5}$ Northam BE, Widdowson GF. The determination of serum albumin by autoanalyser using bromocresol green. Association of Clinical Biochemists' Technical Bulletin 1967; No 11 .

${ }^{6}$ Scott PH, Berger HM, Kenward C, Scott P, Wharton BA. Plasma alkaline ribonuclease (EC 1.4.22) and nitrogen retention in low-birthweight infants. Br $\mathcal{F}$ Nutr 1978;40:459-64.
7 Thomson AM, Billewicz WZ, Hytten FE. The assessment of fetal growth. Fournal of Obstetrics and Gynaecology of the British Commonwealth 1968;75:903-16.

* Gore S. Assessing clinical trials-trial discipline. Br Med f 1981 ;283 211-3.

${ }^{9}$ Rush D, Stein Z, Susser M. A randomized controlled trial of prenatal nutritional supplementation in New York City. Pediatrics 1980;65: 685-97.

${ }^{10}$ Lechtig A, Habicht JP, Delgado H, Klein RE, Yarbrough C, Martorell R. Effect of food supplementation during pregnancy on birthweight. Pediatrics $1975 ; 56: 508-19$.

11 Lechtig A, Delgado H, Lasky R, et al. Maternal nutrition and fetal growth in developing countries. Am $\mathcal{F}$ Dis Child 1975;129:553-6.

12. Briend A. Fetal malnutrition-the price of upright posture. $\mathrm{Br}$ Med $\mathcal{F}$ 1979 ;ii:317-9.

(Accepted 4 fune 1982)

\title{
Dietary protein energy supplementation of pregnant Asian mothers at Sorrento, Birmingham. II: Selective during third trimester only
}

O A C VIEGAS, P H SCOTt, T J COLE, PHyllis EATON, P G NEEDHAM, B A WhARTON

\begin{abstract}
Unselective dietary protein energy supplementation of Asian mothers at Sorrento Maternity Hospital did not enhance intrauterine growth. The effect of selective supplementation was therefore studied. Forty-five mothers who at 28 weeks were known to be nutritionally at risk (triceps increment $\leqslant 20 \mu \mathrm{m} /$ week between 18 and 28 weeks) received one of three supplements during the third trimester: (a) vitamins only-a multivitamin sachet daily containing vitamins $A, B, C$, and $D$; (b) energy42-125 MJ (10 000-30 $000 \mathrm{kcal})$, all from carbohydrate, plus vitamins; (c) protein energy-energy and vitamins as before, but with $5-10 \%$ of energy from milk protein. Eighty-three mothers regarded as adequately nourished at 28 weeks also received one of the three supplements. In the nutritionally at-risk mothers the protein energy supplement was associated with a heavier crude birth weight and heavier weight for gestational age. Supplementation did not lead to improved intrauterine growth in those mothers who were adequately nourished.

The differential effect of supplementation depending on the mothers' nutritional state during the second trimester may explain apparently conflicting results of other studies where some have shown a substantial effect of supplementation and others only a small effect. This effect of intervention is further evidence that "poor
\end{abstract}

Sorrento Maternity Hospital, Birmingham B13 9HE

O A C VIEGAS, DA, MRCOG, Mary Crosse research fellow in perinatal medicine

PHYLLIS EATON, BSC(NUT), SRD, research dietitian

P G NEEDHAM, FRCS, MRCOG, consultant obstetrician

B A WHARTON, MD, FRCP, consultant paediatrician

Selly Oak Hospital, Birmingham B29

P H SCOTT, BSC, PHD, senior biochemist

MRC Dunn Nutrition Unit, Cambridge CB4 1XJ

T J COLE, MA, BPHIL, statistician, member of scientific staff nutrition" contributes to poor intrauterine growth in selected mothers, even in developed countries.

\section{Introduction}

Unselective dietary protein energy supplementation of all Asian mothers at Sorrento Maternity Hospital irrespective of nutritional state during the second and third trimesters of pregnancy did not enhance intrauterine growth. ${ }^{1}$ This study examines the effect of selective supplementation-that is, in which dietary supplements were given to mothers during the third trimester if anthropometric evidence of undernutrition had been detected in the second trimester. It also describes the effect of giving supplements to mothers who had no preceding evidence of undernutrition.

\section{Methods}

PLAN OF TRIAL

We recruited to the trial 130 women who booked between 5 November 1979 and 11 June 1980 before 20 weeks of gestation, who lived within a defined area of the City of Birmingham (covered by domiciliary midwives' areas 9 and 10, Birmingham Area Health Authority (Teaching)), and who gave informed consent. They entered the trial at 18 to 20 weeks but received only iron ( $3 \mathrm{mg}$ daily) and vitamin $\mathrm{C}$ ( $30 \mathrm{mg}$ daily) until 28 weeks (fig 1 ). The mothers were then divided into $(a)$ those who from evidence of other work at this hospital ${ }^{2}$ were nutritionally at risk of having a light for gestational age baby as shown by an inadequate increase in triceps skinfold thickness increment $(\leqslant 20 \mu \mathrm{m} /$ week during the second trimester $\mathrm{n}=45$ ), and $(b)$ those with an adequate increase in triceps skinfold thickness increment ( $>20 \mu \mathrm{m} /$ week) during the second trimester; these are referred to as adequately nourished $(n=85)$.

\section{SUPPLEMENTATION REGIMEN}

Members of each group were then assigned at random to one of three supplement groups: $\mathrm{Vi}$, a multivitamin sachet (Orovite 7 ); EnVi, a multivitamin sachet plus glucose syrup (Hycal) providing 
$1.8 \mathrm{MJ}$ (425 kcal) daily-that is, $125 \mathrm{MJ}(30000 \mathrm{kcal})$ from 28 to 38 weeks; PrEnVi, as for EnVi but with $10 \%$ of energy provided by protein in chocolate-flavoured skimmed-milk powder (40 g daily). This regimen provided about one and a half times the extra recommended dietary allowance, ${ }^{3}$ and we considered it necessary to give a "balanced" supplement by including multivitamins. Distribution and collection was as described. ${ }^{1}$

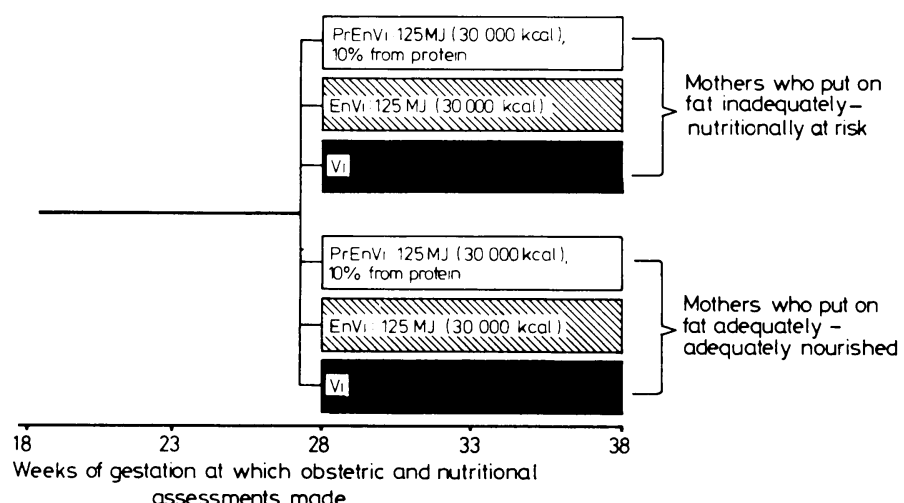

FIG 1-Plan of supplementation trial. Selective. ( $\mathrm{V} i=$ Multivitamin sachet. En=Energy, all from carbohydrate. $\mathrm{Pr}=$ Protein from skimmed milk.)

PATIENTS

The patients were similar to those described in the study of unselective supplementation ${ }^{1}$ (table I). The EnVi group contained more Moslems from Pakistan and therefore fewer vegetarians and more consanguineous marriages. The PrEnVi group contained more Hindus and therefore more vegetarians. The size of the mothers was similar in the three groups.

TABLE I-Details of mothers studied

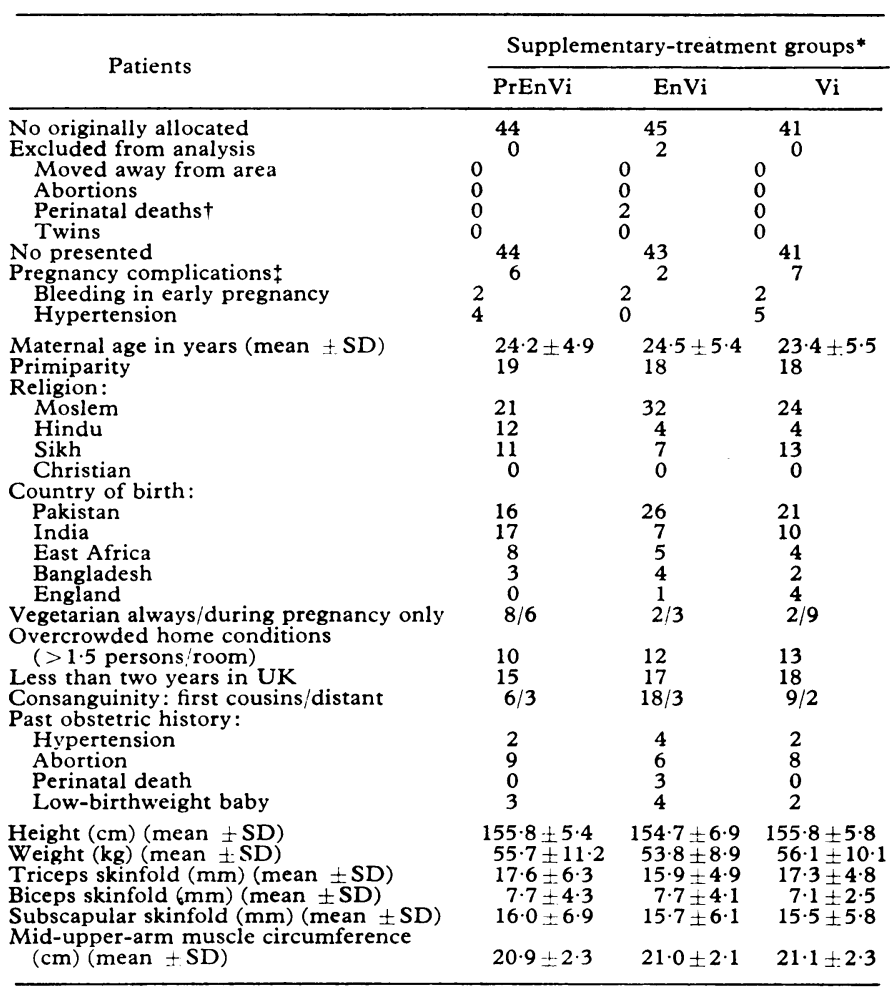

* $\mathrm{Pr}=$ Protein from skimmed milk. En=Energy, all from carbohydrate. $\mathrm{Vi}=$ Multivitamin sachet.

†The two neonatal deaths due to $(a)$ osteogenesis imperfecta and $(b)$ probable inborn tNo mothers smoked.
ASSESSMENT OF PATIENTS AND ANALYSIS OF DATA

The patients attended for obstetric, anthropometric, and biochemical assessment at five-week intervals exactly as before. ${ }^{1}$ More detailed dietary assessments were made, including 24-hour recalls and weighed diet periods of three to seven days. The results will be published elsewhere.

The data were analysed and are presented as before-that is, size at birth is presented as crude birth weight, weight centiles according to Thomson et $a l^{4}$ and internal Sorrento data. As before, the major analysis is as a "pragmatic clinical trial" determine whether a protein energy supplement offered selectively to nutritionally at-risk mothers would enhance intrauterine growth; this analysis includes all Asian mothers entering the trial who gave birth to liveborn singletons at Sorrento who survived the neonatal period. The results were then reanalysed as an "explanatory clinical trial"s to determine whether a protein energy supplement consumed by nutritionally at-risk mothers (but otherwise having a normal pregnancy) led to improved intrauterine growth. To achieve this we excluded from the analysis $(a) 14$ mothers (six in the PrEnVi, one in the EnVi, and seven in the Vi groups) with pregnancies complicated by vaginal bleeding or hypertension or both, and (b) 12 mothers (five in the PrEnVi, four in the EnVi, and three in the Vi groups) who failed to comply with the supplementation regimen-that is, who consumed less than $42 \mathrm{MJ}$ (10000 kcal) or less than $5 \%$ of energy as protein (PrEnVi group) or less than 23 multivitamin sachets ( Vi group). Average consumption of supplement was PrEnVi $88 \mathrm{MJ}$ $(21000 \mathrm{kcal}), 563 \mathrm{~g}$ protein, and EnVi $92 \mathrm{MJ}(21900 \mathrm{kcal})$ from 28 to 38 weeks.

\section{Results}

The results are presented for the nutritionally at-risk mothers (those with an inadequate increase in triceps thickness) and for the adequately nourished mothers (those with an adequate increase in triceps thickness).

\section{MATERNAL ANTHROPOMETRY}

Nutritionally at-risk mothers who received PrEnVi had a mean weight gain in the third trimester of $480 \mathrm{~g}$ a week. This was greater than in those receiving EnVi and $\mathrm{Vi}(304 \mathrm{~g}$ and $312 \mathrm{~g} ; \mathrm{p} \approx 0.08)$ and about the same as in the adequately nourished group (506 $\mathrm{g}$ ) (fig 2). Most of the other anthropometric measurements were in the same direction but the differences did not reach statistical significance.

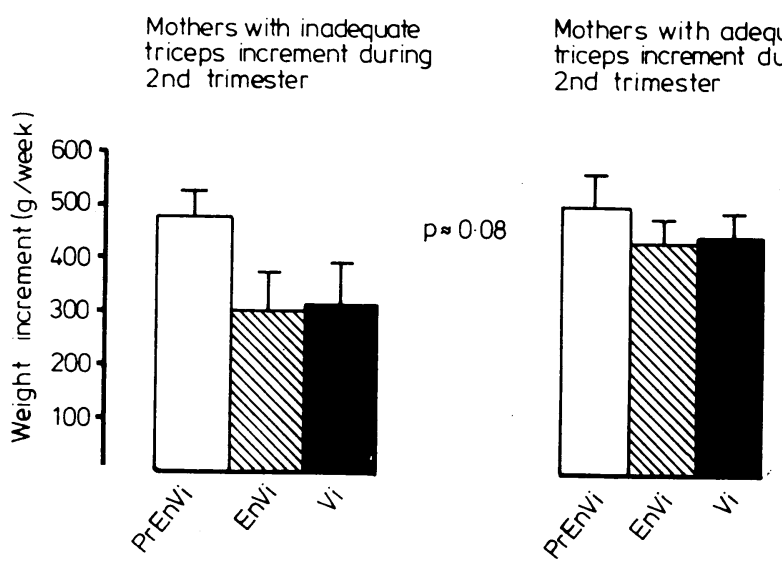

FIG 2-Mean ( \pm SE) weight increments ( $\mathrm{g} /$ week) in mothers given supplements from 28 weeks. Value of $p$ shows significance of difference between PrEnVi and Vi groups. Values of $\mathrm{p}$ greater than 0.09 not shown. (Key to groups as in fig 1.)

\section{MATERNAL BIOCHEMISTRY}

The nutritionally at-risk mothers receiving the vitamin supplement had a significantly higher plasma calcium concentration than the other two groups at 33 and 38 weeks. This difference was not seen in the adequately nourished group and there were no other bio- 
TABLE II-Birth weight, birthweight centile,* and placental weight in mothers given supplements from 28 weeks of pregnancy. Results when data reanalysed as "explanatory clinical trial." $\dagger$ (Results expressed as means $\pm S D$ )

\begin{tabular}{|c|c|c|c|c|c|c|c|c|}
\hline \multirow{2}{*}{ Measurement } & \multicolumn{4}{|c|}{ Mothers who put on fat inadequately } & \multicolumn{4}{|c|}{ Mothers who put on fat adequately } \\
\hline & $\begin{array}{l}\text { PrEnVi } \\
(\mathrm{n}=12)\end{array}$ & $\begin{array}{c}\text { EnVi } \\
(n=15)\end{array}$ & $\begin{array}{c}\mathrm{Vi} \\
(\mathrm{n}=12)\end{array}$ & $\mathrm{p}_{\ddagger}^{\ddagger}$ & $\begin{array}{l}\text { PrEnVi } \\
(\mathrm{n}=21)\end{array}$ & $\begin{array}{c}\text { EnVi } \\
(n=23)\end{array}$ & $\begin{array}{c}\mathrm{Vi} \\
(\mathrm{n}=19)\end{array}$ & $\mathrm{p}_{\ddagger}^{\ddagger}$ \\
\hline $\begin{array}{l}\text { Crude birth weight (g) } \\
\text { Gestational age (weeks) } \\
\text { Thomson SD score } \\
\text { Sorrento SD score }\end{array}$ & $\begin{array}{l}3350 \pm 470 \\
38 \cdot 8 \pm 1 \cdot 3 \\
0 \cdot 16 \pm 0 \cdot 91 \\
0 \cdot 68 \pm 0 \cdot 91\end{array}$ & $\begin{array}{c}2900 \pm 660 \\
37 \cdot 5: 2 \cdot 5 \\
-0 \cdot 12: 0.98 \\
0 \cdot 26 \pm 1 \cdot 16\end{array}$ & $\begin{array}{c}3020 \pm 260 \\
39 \cdot 3 \pm 1 \cdot 2 \\
-0.56 \pm 0.55 \\
-0.23 \pm 0.61\end{array}$ & $\begin{array}{l}\approx 0.05 \\
\text { NS } \\
<0.05 \\
<0.02\end{array}$ & $\begin{array}{c}2940 \pm 400 \\
39.0 \pm 1.5 \\
-0.52 \pm 0.73 \\
-0.21 \pm 0.88\end{array}$ & $\begin{array}{c}3080 \pm 480 \\
29 \cdot 2 \pm 1 \cdot 2 \\
-0 \cdot 36 \pm 1 \cdot 00 \\
0 \cdot 00 \pm 1.06\end{array}$ & $\begin{array}{c}3210 \pm 420 \\
39 \cdot 2 \pm 1 \cdot 0 \\
-0 \cdot 16 \pm 0 \cdot 76 \\
0 \cdot 28 \pm 0 \cdot 80\end{array}$ & $\begin{array}{l}\approx 0.06 \\
\text { NS } \\
\text { NS } \\
\approx 0.08\end{array}$ \\
\hline $\begin{array}{l}\text { Head circumference }(\mathrm{cm}) \\
\text { Length }(\mathrm{cm}) \\
\text { Triceps skinfold }(\mathrm{mm}) \\
\text { Biceps skinfold }(\mathrm{mm}) \\
\text { Subscapular skinfold (mm) } \\
\text { Suprailiac skinfold (mm) } \\
\text { Mid-upper-arm muscle circumference }(\mathrm{cm})\end{array}$ & $\begin{array}{l}34 \cdot 7 \pm 1 \cdot 0 \\
50 \cdot 3 \pm 2 \cdot 2 \\
4 \cdot 05 \pm 1 \cdot 2 \\
3 \cdot 32 \pm 0 \cdot 9 \\
4 \cdot 03 \pm 1 \cdot 3 \\
3 \cdot 60 \pm 1 \cdot 1 \\
9 \cdot 58 \pm 0 \cdot 86\end{array}$ & $\begin{array}{l}33 \cdot 8 \pm 1 \cdot 9 \\
49 \cdot 1 \pm 4 \cdot 1 \\
3 \cdot 43 \pm 0 \cdot 6 \\
2 \cdot 83 \pm 0.5 \\
3.73 \pm 0 \cdot 7 \\
3 \cdot 50 \pm 0 \cdot 8 \\
8.92 \pm 1.41\end{array}$ & $\begin{array}{l}34 \cdot 1 \pm 1 \cdot 0 \\
49 \cdot 8 \pm 1 \cdot 8 \\
3 \cdot 35 \pm 0 \cdot 4 \\
2 \cdot 93 \pm 0.3 \\
3 \cdot 44 \pm 0 \cdot 7 \\
3 \cdot 38 \pm 0 \cdot 9 \\
9 \cdot 30 \pm 0.42\end{array}$ & $\begin{array}{l}\text { NS } \\
\text { NS } \\
\approx 0.08 \\
\text { NS } \\
\text { NS } \\
\text { NS } \\
\text { NS }\end{array}$ & $\begin{array}{l}33 \cdot 9 \pm 1 \cdot 2 \\
49 \cdot 2 \pm 2 \cdot 8 \\
3 \cdot 36 \pm 0.5 \\
2 \cdot 77 \pm 0.5 \\
3 \cdot 30 \pm 0 \cdot 4 \\
3 \cdot 26 \pm 0 \cdot 6 \\
9 \cdot 09 \pm 0.53\end{array}$ & $\begin{array}{l}34 \cdot 3 \pm 1 \cdot 4 \\
50 \cdot 4 \pm 3 \cdot 2 \\
3 \cdot 61 \pm 0 \cdot 6 \\
3 \cdot 18 \pm 0.5 \\
3 \cdot 60 \pm 0 \cdot 7 \\
3 \cdot 42 \pm 0 \cdot 7 \\
9 \cdot 10 \pm 0.80\end{array}$ & $\begin{array}{l}34 \cdot 9 \pm 1 \cdot 2 \\
50 \cdot 9 \pm 2 \cdot 3 \\
3 \cdot 75 \pm 0.7 \\
3 \cdot 38 \pm 0.8 \\
3 \cdot 88 \pm 0 \cdot 7 \\
3 \cdot 72 \pm 0.8 \\
9 \cdot 31 \pm 0.58\end{array}$ & $\begin{array}{l}<0.02 \\
<0.05 \\
\approx 0.06 \\
<0.01 \\
<0.005 \\
\approx 0.05 \\
\text { NS }\end{array}$ \\
\hline Placental weight $(\mathrm{g})$ & $641 \pm 80$ & $601 \pm 129$ & $555 \pm 64$ & $<0.02$ & $582 \pm 126$ & $605 \pm 91$ & $603 \pm 99$ & NS \\
\hline
\end{tabular}

*Birthweight centile for gestational age, sex, parity, and maternal height according to data of Thomson et al* and internal Sorrento data (see Methods).

†"Explanatory clinical trial": after exclusion of pathological pregnancies and poor compliers (see Methods).

† Values of $p$ indicate significance of difference between PrEnVi and Vi groups. NS $=p>0.09$.

chemical differences. Table A (available on request) gives the detailed biochemical results.

\section{SIZE OF BABY AT BIRTH}

Clear differences in intrauterine growth in the two groups were observed (fig 3). Nutritionally at-risk mothers who received PrEnVi

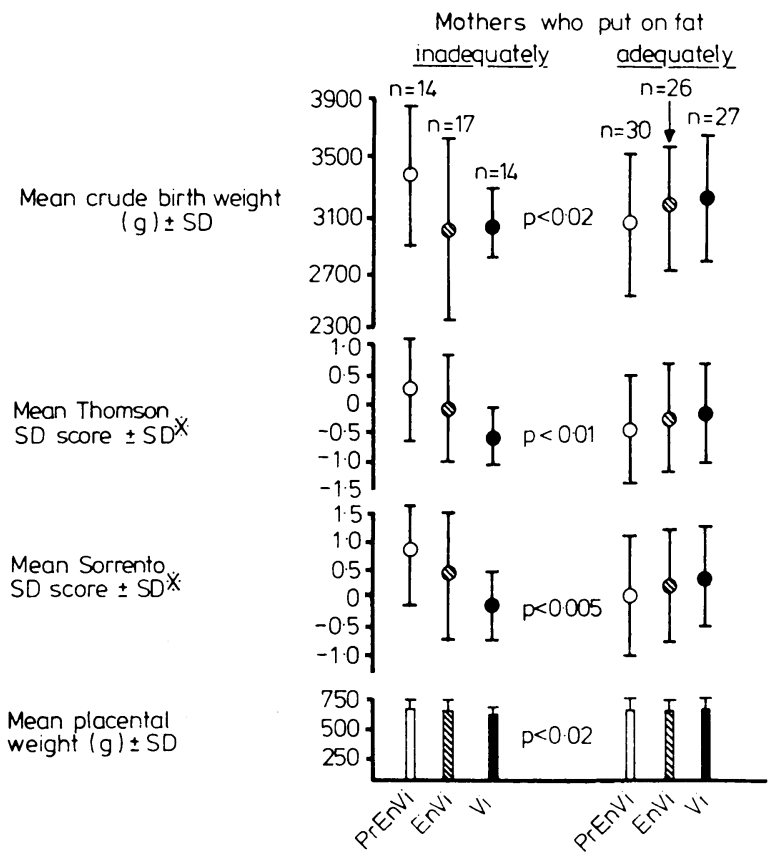

FIG 3-Birth weight, birthweight centile, ${ }^{*}$ and placental weight in mothers given supplements from 28 weeks of pregnancy. Values of $p$ indicate significance of difference between PrEnVi and Vi groups. Values of p greater than 0.09 not shown. (Key to groups as in fig 1.)

*Birthweight centile for gestational age, sex, parity, and maternal height according to data of Thomson et $\mathrm{al}^{4}$ and internal Sorrento data (see Methods).

had heavier placentas and gave birth to babies with a heavier crude birth weight $(+310 \mathrm{~g})$ and higher weight centiles. Other measurements of the babies were similarly greater in the PrEnVi group but only the greater triceps skinfold thickness reached statistical significance $(\mathrm{p}<0.05)$.

In the mothers who had put on fat adequately protein energy supplementation did not lead to improved intrauterine growth. Indeed their mean crude birth weight and weight centile were lower than in the Vi group but not significantly so. The other body measurements of these babies were similarly less but only the differences in biceps and subscapular skinfold thicknesses reached statistical significance. Table B (available on request) gives all the numerical details summarised in fig 3 together with the detailed anthropometric values of the babies in the six groups.

When the results were reanalysed as an explanatory clinical trial (table II) the nutritionally at-risk mothers who received PrEnVi were again shown to have had babies with a heavier crude birth weight and a higher weight for gestational age. Again, protein energy supplementation did not lead to improved intrauterine growth in the mothers who had put on fat adequately; indeed the crude birth weight in the PrEnVi group was less than in the Vi group $(p \approx 0.06)$ and so was the Sorrento weight standard deviation score $(p \approx 0.08)$.

\section{Discussion \\ PRESENT STUDY}

Consumption of the protein energy supplement led to improved intrauterine growth in women who were at nutritional risk of having a poorly grown baby. Three points require consideration before accepting this conclusion. The PrEnVi group contained more Hindus but, since they tend to have a lower birth weight, this would not have given the PrEnVi group any advantage. When the patients are divided according to supplement and triceps skinfold thickness increment the numbers in the subgroups are relatively small, but the twotailed statistical significance of differences between the small subgroups is given. We therefore regard the conclusion as valid. Was the protein energy by itself responsible for the enhanced growth or could it have been due to protein alone or some micronutrient within the chocolate-skimmed milk powder? This cannot be excluded with certainty but, since the results in the EnVi group were mostly midway between those of the PrEnVi and Vi groups, it seems more likely that the "nutrient" which enhanced growth in this study was balanced protein energy.

\section{COMPARISON WITH OTHER SUPPLEMENTATION STUDIES}

In some early studies improved diet was not the only variable since it was often accompanied by increased obstetric care. In the past 10 years there have been four other major supplementation studies ${ }^{6-9}$ with variation in choice of controls and methods to check compliance and exclusion policy etc. The major features of these studies are given in table $\mathrm{C}$ (available on request)

We suggest that the results of our study-namely, a differential effect of supplementation depending on the mothers' nutritional state during the second trimester-may explain the apparently conflicting results of the other studies. Some showed a substantial effect-for example, in Guatemala ${ }^{6}$ and Colombia ${ }^{7}$; we suspect that most of these mothers were nutritionally at risk. 
Others had only a small effect-for example, in New York ${ }^{8}$ and Taiwan $^{9}$; we suspect that very few of these mothers were nutritionally at risk of having a poorly grown baby.

\section{IMPLICATIONS FOR INTERVENTION POLICY}

Clearly this and our other study' show that it would be inappropriate to give supplements to all Asian mothers. Selection is essential. An inadequate gain in triceps skinfold thickness during the second trimester seems a suitable method for identifying the nutritionally at-risk mothers. Since the increase in triceps skinfold thickness represents, in effect, a person's energy balance we suspect that this is a better indicator of nutritional risk than assessment of dietary intake, but we are studying this further. The method is certainly simple, cheap, and applicable to large numbers of patients, but unfortunately it will not be possible to apply this to mothers booking very late. Once the mother is selected at 28 weeks as being nutritionally at risk, should she be given a supplement-the logistics are daunting - or would dietary advice alone do ?

Ways of expanding these experimental observations into a routine service are being examined.

We are grateful to $\mathrm{Mr} \mathrm{H} \mathrm{N}$ Mansfield, consultant obstetrician, for allowing us to study patients under his care; Mr P Scott, head of the biochemistry department, Selly Oak Hospital; Mrs J King, research midwife; Miss K Snow, medical illustrations department, Birmingham Children's Hospital; the community midwives of areas 9 and 10; Mrs P Cox for secretarial help; and Beecham Research Laboratories, who provided the nutritional supplements.
Tables A, B, and C may be obtained from Dr B A Wharton.

\section{References}

1 Viegas OAC, Scott PH, Cole TJ, Mansfield HN, Wharton P, Wharton BA. Dietary protein energy supplementation of pregnant Asian mothers at Sorrento, Birmingham. I: Unselective during second and third trimesters. Br Med f 1982;285:589-92.

" Bissenden JG, Scott PH, King J, Hallum J, Mansfield HN, Wharton BA. Anthropometric and biochemical changes during pregnancy in Asian and European mothers having light for gestational age babies. $\mathrm{Br} \mathcal{F}$ Obstet Gynaecol $1981 ; 88: 999-1008$.

${ }^{3}$ Department of Health and Social Security. Recommended daily amounts of food energy and nutrients for groups of people in the United Kingdom. Reports on health and social subjects. No 15. London: HMSO, 1979.

${ }^{4}$ Thomson AM, Billewicz WZ, Hytten FE. The assessment of fetal growth. fournal of Obstetrics and Gynaecology of the British Commonwealth 1968;75:903-16.

${ }^{5}$ Gore S. Assessing clinical trials-trial discipline. Br Med $\mathcal{F} 1981$;283: 211-3.

${ }^{6}$ Lechtig A, Habicht JP, Delgado H, Klein RE, Yarbrough C, Martorell R. Effect of food supplementation during pregnancy on birthweight. Pediatrics 1975;56:508-19.

7 Mora JO, de Paredes B, Wagner M, et al. Nutritional supplementation and the outcome of pregnancy. I. Birth weight. Am F Clin Nutr 1979; $32: 455-62$.

${ }^{8}$ Rush D, Stein Z, Susser M. A randomized controlled trial of prenatal nutritional supplementation in New York City. Pediatrics 1980;65: 685-97.

9 Blackwell RO, Chow BF, Chinn KSK, Blackwell B, Hsu SC. Prospective maternal nutrition study in Taiwan: rationale, study design, feasibility and preliminary findings. Nutrition Reports International 1973;7: 517-32.

(Accepted 4 fune 1982)

\title{
Influence of previous gold toxicity on subsequent development of penicillamine toxicity
}

\author{
P J SMITH, W R SWINBURN, D R SWINSON, I M STEWART
}

\begin{abstract}
The incidence of penicillamine toxicity was determined in 250 patients who had never previously received gold, 76 patients who had received gold without toxic reaction, and 79 patients with a previous history of gold toxicity. The results suggest that there may be a higher incidence of penicillamine toxicity in patients who have previously shown toxic reactions. The interval between stopping the gold and starting the penicillamine did not influence incidence of toxicity. The development of a rash during gold treatment does not seem to influence the development of a rash during penicillamine treatment, but patients who have had proteinuria or bone-marrow depression during gold treatment may have an increased likelihood of developing a similar side effect with penicillamine.
\end{abstract}

Wrightington Hospital, Appley Bridge, Nr Wigan, Lancs WN6 9EP P J SMITH, MRCP, consultant rheumatologist W R SWINBURN, MRCP, consultant rheumatologist

D R SWINSON, MRCP, consultant rheumatologist

I M STEWART, MRCP, consultant rheumatologist

\section{Introduction}

There have been conflicting reports on the effect of previous gold treatment on the subsequent development of penicillamine toxicity. The multicentre trial group found no increased toxicity in patients who had previously received gold treatment. ${ }^{1}$ Webley and Coomes also reported no overall increase in the incidence of side effects, but rashes and possibly bone-marrow depression were commoner in patients who had previously received gold. ${ }^{2}$ Dodd $e t$ al found an increased penicillamine toxicity in patients who had previously had adverse reactions to gold and also an increased risk if the penicillamine was given within six months of stopping the gold. ${ }^{3}$ Steven et al concluded that there was no increased incidence of toxic reaction to second-line drugs in patients who had previously been treated with gold or penicillamine and that the interval between the drugs had no influence on the outcome. ${ }^{4}$

\section{Patients, methods, and results}

The records of 405 patients with rheumatoid arthritis who had been given penicillamine were studied. A total of 250 had never received gold, 76 had received gold without adverse effects, and 79 had a history of gold toxicity. In all cases of toxicity the side effects were considered sufficiently severe to stop the drug; mild or transient side effects have not been included. Patients with upper gastrointestinal 